\title{
Modos de compreender imagens: questões de método sobre a análise textual das representações visuais
}

Benjamim Picado

\section{Resumo}

Propomos um panorama breve dos pontos de contato entre as abordagens semióticas e estéticas da análise das imagens, tendo em vista o regime discursivo que as demarca, especialmente no contexto da comunicação: reconhecendo a predominância histórica das perspectivas que a semiologia aportou à discussão sobre as regências textuais das representações visuais, procuramos introduzir ao debate o ponto de vista que as ciências da arte (muito especialmente as questões de método da abordagem histórica dos fatos artísticos), supondo encontrar aí certos modos de aproximação à estrutura psicológica da experiência dos ícones e de sua interpretação e fruição que não poderiam ser negligenciadas por uma teoria da compreensão da imagem enquanto forma textual. Palavras-chave

Análise de imagens. Semiótica. Ciências da arte.

\section{Benjamim Picado | jbpicado@hotmail.com}

Doutor em Comunicação e Semiótica pela Pontifícia Universidade Católica de São Paulo - PUCSP. Professor da Faculdade de Comunicação e do Programa de Pós-Graduação em Comunicação e Cultura Contemporâneas da Universidade Federal da Bahia - UFBA.

\section{A regência discursiva da imagem: um desafio metodológico}

Há um registro determinado no qual algo a que podemos chamar de "questão da imagem" atormenta os espíritos, em especial quando é evocada em nosso campo de estudos, com algum grau de centralidade. Trata-se, em primeiro lugar, de um gênero de interrogações que, a título da abordagem problemas atinentes a outras áreas de conhecimento, ainda assim aporta questões muito peculiares a esse universo de fenômenos: assim sendo, ao se perguntar sobre a imagem, a filosofia da arte se interessa sobretudo pelo suposto status representacional dos ícones visuais; por seu turno, a história da arte se pergunta sobre as matrizes do problema da evolução dos estilos pictóricos, em diferentes épocas.

Entretanto, como já dissemos, algo de muito próprio inspira os estudos sobre fenômenos e processos comunicacionais, quando neles a imagem é interpelada enquanto objeto de atenção: a finalidade comunicacional das representações visuais e o diagnóstico sobre a imensa impregnação da cultura de nossos dias 
pelas imagens são ambas decorrentes da ênfase com a qual nossa área de estudos associa os ícones visuais com formas discursivas, estratégias retóricas e funções narrativas que lhe seriam próprias.

0 prolongamento desse tipo de interesse pelos regimes discursivos da imagem parece-nos haver chegado a um tal ponto de resolução que poderíamos inclusive ensaiar certos modelos de uma hipotética redução das formas da representação visual aos princípios de organização de uma ordem discursiva determinada. Em nosso percurso de pesquisa e estudos, mencionamos essa idéia de uma possível matriz da discursividade visual, o resultado mais evidente da sedimentação do interesse das teorias da comunicação pela questão da imagem.

Por mais de uma vez, em nossas próprias investigações, procuramos explorar os eixos teórico-metodológicos das abordagens que privilegiaram, no estudo das representações visuais, seus aspectos de regência por variadas formas da expressão discursiva: dado de pressuposto dessa exploração é o reconhecimento de que o problema dessa regência mesma é que caracterizou a pertinência com a qual a questão da função das representações visuais foi historicamente tematizada em nosso campo de estudos (PICAD0, 2005)

Com esse mesmo fim, já identificamos, em vários capítulos de nossas explorações, uma espécie de contaminação que as ciências da linguagem infundiram na compreensão sobre 0 fato de que as imagens preenchem funções próprias do discurso (seja do ponto de vista de sua expressão, seja na perspectiva de sua apreciação e compreensão): caso exemplar aqui é o dos primeiros ensaios de uma semiologia visual, encarnada nas formulações originárias de Roland Barthes (1964) e no modo como nela se estabelecem os princípios da redução da iconicidade das representações visuais às matrizes lingüísticas da compreensão e da expressão (PICAD0, 2003).

Na perspectiva de uma "semiologia de primeira geração", o aspecto de manifestação propriamente icônico (ou analógico) das representações visuais ficaria sempre legado ao que chamamos alhures (ecoando uma sugestão do próprio Barthes) de uma certa insignificância originária do status semiológico da imagem. Nessa perspectiva de análise (prolongada por muitos dos estudos comunicacionais), a regência discursiva das imagens implicaria sempre 0 concurso de estruturas lingüísticas, às quais a expressão e fruição das formas visuais ficaria necessariamente subordinada (PICAD0, 2004).

Supomos que muitos dos aspectos dessa discussão são, na verdade, decorrentes de uma má-apreensão quanto ao caráter das proposições originárias de uma semiologia visual, mas que não devem ser combatidas antes de uma avaliação do terreno heurístico de base dessas mesmas proposições. Ao avaliarmos as teses desta 
primeira semiologia, preferimos, portanto, adotar uma postura um pouco diferente daquela que caracteriza nosso campo de estudos: em geral, discussões dessa natureza apenas aprofundam uma certa impressão de um debate entre escolas semióticas, mais do que propriamente uma discussão sobre esse fenômeno determinado que é 0 das regências textuais próprias aos materiais visuais no contexto da comunicação.

Em nosso entendimento, um caminho alternativo é, antes de mais nada, o de um aggiornamento de alguns outros endereços teóricos da análise de materiais visuais: nos definimos mais especificamente pelas questões de método das abordagens de materiais expressivos da comunicação visual, com especial ênfase nas vizinhanças possíveis entre a abordagem textual da análise da imagem e as contribuições aportadas pelo campo das teorias da arte, em geral.

Ressentimo-nos, por vezes, do fato de que a aproximação metodológica de nosso próprio campo de estudos ao universo da produção, da fruição e da interpretação das imagens não pareceu valorizar suficientemente a importante fortuna nocional e metodológica da análise que as chamadas ciências da arte (aí compreendidas as teorias poéticas, estéticas e a própria história da arte) aportaram de maneira permanente e continuada para essa discussão sobre 0 valor comunicacional intrínseco ao universo dos ícones visuais, sobretudo em suas manifestações de vínculo com as estratégias retóricas e narrativas dos meios de comunicação massivos.

Se pudéssemos conjurar as interessantes questões que todas essas teorias devotadas ao campo do artístico trouxeram para uma aproximação metodologicamente rentável à dimensão discursiva da imagem, poderíamos decerto nos preparar para superar essa espécie de "fosso disciplinar" que, por vezes, parece dificultar que falemos do universo iconográfico de nossa época, especificando nele aspectos de sua realização enquanto acervo de estratégias e de mensagens estruturadas na forma de textos e, na mesma medida, organizadas a partir de materiais que foram elaborados tendo em vista sua possível fruição sensível por parte de sua recepção.

Nesse caso, teríamos que considerar forçosamente o papel de uma abordagem dos materiais da cultura mediática mais inspirada por questões oriundas, por exemplo, das teorias estéticas, de um modo geral. Nesses termos, a questão do valor textual da imagem passaria a ter uma menor correlação com o problema de sua hipotética redução às estruturas lingüísticas do discurso enunciativo, e mais com aspectos de provocação que as imagens podem suscitar de nossos juízos perceptivos e de nossos modos de contemplação e fruição propriamente visuais.

Ainda assim, entretanto, o fato de que estamos tratando de imagens que se definem pelo seu valor discursivo (pelo modo como se coordenam com funções próprias à compreensão de sentenças 
e frases, em contextos narrativos, reportativos ou retóricos, por exemplo) deverá fazer- nos vislumbrar a dimensão estética dessa manifestação na sua estrita correlação com as finalidades comunicacionais desses gêneros de ícones.

Nesse ponto, o caráter propriamente estético de sua manifestação encontra-se delimitado pelos aspectos inevitavelmente discursivos do agenciamento no qual encontramos submetido o regime da produção e da recepção da imagem visual na contemporaneidade. E, nesse sentido, finalmente, podemos dizer que uma interrogação às regências discursivas das imagens, em contextos mediáticos (e sob uma ênfase nos aspectos propriamente visuais da manifestação desta regência), concerniria possivelmente ao universo daquilo que muitos autores chamam de uma "estética da comunicação".1

\section{Palavra, imagem e a iconicidade das formas textuais}

Propomos assim que uma abordagem desses aspectos de regência textual das imagens no contexto da cultura mediática deverá ser complementada por um discurso teórico (e de resultantes metodológicas mais claras) sobre as funções propriamente comunicacionais ligadas à modelação icônica das representações visuais: desse modo, a questão da significação textual das imagens visuais não estará restrita àqueles aspectos que definem a redução de suas propriedades visuais às funções do discurso enunciativo ou narrativo, mas também incorporaria algum discurso teoricamente bem fundado (e capaz de impregnar amplas regiões do fenômeno representacional na imagem) sobre os aspectos propriamente plasticoicônicos de sua manifestação.

Em determinados ramos da investigação sobre a imagem, é o problema mais elementar da presença de formas textuais no corpo icônico das representações visuais que motivou uma indagação sobre as relações entre imagem e discurso. Esse problema nem sempre foi exclusivo das abordagens semiológicas, muito embora 0 campo da comunicação tenha se comportado como se esse fôsse 0 caso (assumindo inclusive um certo tipo de perplexidade da qual boa parte dos semiólogos parecem sofrer ao tratar da questão); fora de nosso campo de estudos, não encontramos esse mesmo tipo de perplexidade e de necessidade de estrita demarcação (ou, pior ainda, de redução) entre domínios como os da imagem e do discurso.

0 acordo acerca do real significado de um sintagma como estética da comunicação ainda parece longe de nosso alcance, ao menos naquilo que podemos designar como uma disciplina ou um saber de limites mais ou menos claros: na perspectiva sugerida por autores como Herman Parret (1997), o que se chama por esse nome concerne à questão da essencial comunicabilidade de nossos afetos, e o modo como o domínio da sensibilidade deve ser tomado como matricial da (ou, num linguajar mais próprio, transcendente à) experiência cooperativa na qual as teorias pragmáticas fixaram o problema da compreensão textual, como um todo. Numa outra vertente à qual se faz apelo à idéia de uma estética da comunicação, é a indagação sobre os meios de comunicação que está, por sua vez, no centro das preocupações de uma disciplina como a estética e, nesse caso, trata-se de dimensionar, nos limites próprios a essa disciplina filosófica, toda ordem de interrogações que se lançaram sobre as estratégias expressivas e às estruturas prévias da compreensão mobilizadas por esses mesmos media (CAUNE, 1997). 
Tomemos em tela 0 caso dos historiadores da arte, por exemplo: para eles, em geral, a questão da presença de segmentos textuais no corpo da imagem não é suscitada pelas mesmas obsessões teóricas que ainda afligem os teóricos da significação, mas obviamente por questões próprias ao campo da investigação histórica das formas da expressão visual. Mas, nem mesmo por isso, estão eles privados de um acesso fenomenologicamente interessante ao caso em questão, isto é, às relações entre formas textuais e a matéria icônica da qual se compõe necessarimente uma representação pictórica.

Mesmo para um autor como Gombrich (tão afeito, por seu turno, aos problemas e métodos mais tradicionais do historiador da arte), a questão das relações entre imagem e texto também perpassou seus interesses de especulação, em determinados instantes (GOMBRICH, 1985): em seu caso em especial, essa preocupação se deu a título de uma caracterização das estratégias de programação de efeitos na arte do século XX (portanto, como uma questão ligada à definição dos estilos de certos períodos da modernidade artística). Muito embora tenham se interrogado sobre a incidência de formas textuais no corpo da imagem, a indagação sobre os regimes estruturais de funcionamento textual da representação pictórica constituiu, em geral, uma lacuna na exploração dos historiadores das formas visuais do passado e do nosso tempo. ${ }^{2}$

0 caso de Meyer Schapiro (2000) é uma exceção a esse diagnóstico e um caso particularmente ilustrativo dos pontos de contato entre uma abordagem ao mesmo tempo histórica e semiótica do problema das regências textuais da imagem e, em particular, da questão da presença de segmentos verbais, a título de quaisquer funções que sejam (e, no caso da história da arte, eles nem sempre são da ordem de um favorecimento de funções narrativas ou ficcionais, por exemplo): em primeiro lugar, a questão da presença do texto na imagem é (ao menos para o historiador das imagens) uma questão ligada às exigências às quais a arte da representação esteve submetida, em determinados períodos, sobretudo quando consideramos sua relação com certas instituições como a Igreja, o Estado, o mecenato e mesmo 0 campo da arte, este considerado como espaço de disputas e de negociação de prestígios.

Nesses termos, considerar a questão das relações entre texto e imagem como um traço característico da arte medieval, por exemplo, não é um problema ligado ao estabelecimento de condicionantes de natureza estrutural para o funcionamento textual da imagem, como no

No caso de Gombrich (1983), questões dessa natureza apenas emergem quando ele precisa lidar com as manifestações mais contemporâneas da expressão visual, muito especialmente no campo das artes gráficas e nas modalidades de expressão visual, próprias do universo dos meios de comunicação de massa. As manifestações desse interesse são esparsas pela obra gombricheana, mas destacamos aqui uma referência à análise do trabalho do cartunista Saul Steinberg, objeto da admiração do historiador e assunto de alguns de seus ensaios, mesmo aqueles que encontramos em suas obras mais conhecidas, como Art and Illusion. (GOMBRICH, 1959; 1983). 
caso das abordagens classicamente semiológicas. No caso da exploração histórica da arte cristã do medievo, o estudo sobre a incidência de formas de escitura na matéria visual de pinturas é uma peculiar decorrência do problema mais geral (e muito característico de uma história da cultura), a saber, o da introdução de meios de divulgação como o livro impresso; é precisamente em tais condições que Schapiro (2000) nos introduz a questão das relações entre imagem e texto na arte paleo-cristã do alto medievo; neste mesmo sentido, as questões semiológicas estarão sempre submetidas às condicionantes de uma descrição histórica do fenômeno.

Se desejamos assimilar a fortuna dessa exploração teórica, incorporando-a ao acervo das manifestações mais recentes de uma retórica visual, devemos ser capazes de isolar do trabalho de autores como Schapiro aquilo que é da ordem dos operadores metodológicos de sua análise histórica, de modo a nos reportarmos às estratégias textuais da imagem contemporânea, a partir das mesmas chaves que 0 permitiram descrever esse fenômeno da relação entre texto e imagem em ícones da arte da cristandade.

De qualquer maneira, trata-se aqui de um modo de endereçar questões sobre a periodização dos estilos e tradições da representação visual que é capaz, ao mesmo tempo, de acolher formas de descrição, digamos assim, mais "internas" ao fenômeno, no momento mesmo em que ele é caracterizado na sua vinculação com seu próprio contexto temporal: nesse sentido, Schapiro é reconhecidamente um dos historiadores da arte que, desde muito cedo, mais familiaridade manifestou com respeito aos instrumentais da semiótica e da semiologia para o trabalho de análise histórica das formas representacionais, e sua obra exibe claramemente as provas dessa sensibilidade semiológica requerida ao trabalho do historiador (SCHAPIRO, 1969).

Para além das separações apressadas entre o texto e a imagem, tomadas como naturezas distintas, Schapiro sempre procurou compreender o fenômeno da representação visual a partir da admissão de um regime de integração entre a formas da escritura e da imagem, tomando essa mesma síntese no contexto da forma propriamente visual da representação pictórica (e, nesse sentido, é que pôde assim acolher, com a devida propriedade, os instrumentais de uma semiologia aplicada ao estudo das formas visuais).

Nesses termos, a presença de formas textuais no contexto dos ícones visuais funciona decerto a títulos diversos, mas sempre sob um aspecto no qual a escritura é inerente à imagem mesma, ela é uma das inscrições pelas quais podemos caracterizar os ícones visuais (do mesmo modo que o são as linhas, contornos, cores), uma vez que estes sejam definidos a partir de sua constituição plástica: isso quer dizer que as funções que o texto preenche, seja no plano informacional, descritivo ou narrativo, 
implicam sua assimilação prévia ao plano icônico da representação visual. Esse mesmo fenômeno é evidente, por exemplo, no emprego que fazem dela certas escolas pictóricas do século XIX: os exemplos de Schapiro (bem díspares, por sinal) vêm de Courbet, Manet e de Homer, e dos modos como o recurso à assinatura do pintor é plasticamente integrado às funções figurativas da pintura, muitas vezes até tomado como elemento complementar do fundo da composição, da paisagem ou do cenário interior, por exemplo (SCHAPIR0, 2000).

Por outro lado, Schapiro distingue na arte paleocristã do medievo dois tipos de tratamento da introdução do texto à imagem, um dos quais prima por inscrever a forma da escrita como motivo figurativo (como inscrições alfabéticas em livros e pergaminhos), e outra, na qual a presença de uma escritura como que prenuncia uma função de representação da expressão verbal das personagens do quadro, e que será característica, por sua vez, do uso dos balóes nos quadrinhos. Assim sendo, o uso dos filactérios com o fim de identificar aspectos do que uma personagem ou apóstolo vaticinam (através da fala) implica em um tratamento anti-natural da inserção do verbo na imagem; ainda que os motivos dessa inscrição sejam naturais (um pergaminho que compõe a cena funcionando a título de suporte de uma fala), sua função é a de representar um elemento que a rigor não poderia ser visualizável, na pintura (a não ser através de um recurso arbitrário), isto é, a faculdade da expressão verbal das personagens.
Quando examinamos a questão da presença do texto no interior da imagem, num caso como 0 dos quadrinhos, verificamos que a incidência das formas de uma escritura não possui apenas a função de indicar a fala ou o pensamento das personagens (ou de um narrador, no caso das legendas), mas é igualmente um segmento das próprias formas visuais dessa arte, juntamente com aquelas que definem a caracterização das figuras condutoras da ação: de um lado, temos as formas visuais mesmas que abrigam as incrições (sejam elas da ordem da legenda ou dos balões, que representam a expressão verbal ou o pensamento das personagens); de outro, as inscrições textuais propriamente ditas, e que constituiriam um material à parte da significação icônica, não fossem elas mesmas também investidas de um certo grau de expressividade manifesta numa forma que é propriamente iconico-visual.

Do mesmo modo que Schapiro destaca o valor icônico das inscrições presentes na arte cristã do medievo (pelo modo como a escritura se deixa assimilar pelo contexto plástico da imagem mesma), idenficamos na arte dos quadrinhos o mesmo tipo de assimilação do texto que não 0 converte em um ente estranho à imagem (como se fosse uma espécie de apêndice complementar à função das imagens): certos especialistas chamam-nos a atenção para a necessidade de considerar a questão do texto visual nos quadrinhos como o efeito de uma relação entre segmentos icônicos e verbais 
que opera de uma forma tal que a análise dos segmentos de escritura jamais estará completamente dissociada das funções que são próprias ao segmento visual de sua apresentação (FRESNAULT-DERUELLE, 1970).

Poderíamos multiplicar aqui os casos em que a relação entre formas escritas e formas plásticas se negociam, no modo de construir um sentido discursivo, que associamos às imagens: mas é necessário que nos detenhamos nesse percurso momentaneamente para reconhecer que a questão da significação textual das imagens não deve se restringir exclusivamente a esse plano de relações entre formas de escritura e formas visuais, mas é algo que pode ser abordado no interior da própria estrutura icônica das representações visuais. 0 fato de que assimilamos muitas vezes os ícones a enunciados não decorre do fato de que um texto esteja associado a elas, mas decerto ligado a determinantes que são constitutivas da própria plasticidade da imagem.

\section{Semiose visual e as estruturas da percepção}

Num outro caso (como o da semiótica visual de Umberto Eco), a ordem de problemas se altera substancialmente, mas o ponto que defendemos permanece em sua integridade, isto é: identificamos aqui (agora na perspectiva de trabalho própria de um semioticista) preocupações similares àquelas do historiador da arte, ao propor-se integrar os campos da análise de materiais visuais, levando em conta a variedade dos materiais através dos quais a significação icônica é elaborada.

0 que evidentemente diferencia essas abordagens é decerto a finalidade através da qual se opera essa unificação de métodos de análise, seja na semiótica visual ou nas ciências da arte: já vimos em outras ocasiões que 0 argumento de Eco sobre a possibilidade de se descrever os princípios estruturais das mensagens visuais investia fortemente contra a subordinação do valor comunicacional das imagens aos princípios da significação descritos pela linguística estrutural; desse modo, poder-seia supor que a proposta de Eco investiria numa possível analiticidade ou independência dos códigos icônicos em relação a outras ordens da simbolicidade da compreensão (EC0, 1968).

Essa suposta característica dos códigos visuais decorreria de um aspecto manifesto da perplexidade das teorias semióticas com respeito ao regime discursivo das imagens, a saber, 0 das possíveis diferenças entre a descrição verbal e a representação pictórica: é comum entre os semioticistas (mas também entre certos estetas) que se indague sobre as relações estruturais que se pode estabelecer entre uma figuração visual uma descrição verbal. Do ponto de vista das abordagens semióticas de segunda geração, assume-se que o regime de representação no qual as imagens funcionam não pode ser o mesmo daquele que define os enunciados linguísticos; uma decorrência metodológica dessa admissão é 
a de que os regimes textuais da imagem poderiam ser descritos a partir de uma plataforma não necessariamente lingüística.

Um aspecto interessante das abordagens semióticas de Eco (1968) sobre o regime discursivo da imagem diz repeito à gênese das figuras de base na formação dos semas visuais, em um hipotético código icônico: quando nos indagamos sobre as entidades que originam essas mesmas figuras de uma estrutura da significação icônica, vemos que as regras para a composição de representações não parecem suficientes para explicar como é que compreendemos a relação entre uma imagem e aquilo que ela representa ou significa (supondo especialmente que a significação da imagem seja um modo que lhe é próprio de dizer alguma coisa).

Na melhor das hipóteses, essas mesmas regras são apenas cristalizações momentâneas de um certo modo de pensar a ligação entre as imagens e seu fundamento ou seus temas visuais, mas não exprimem, per se, esse mesmo fundamento pelo qual os ícones se restituem a seus objetos, enquanto parte de uma estrutura inerente a seu funcionamento representacional.

Nessas condições, há que considerar que 0 código das representações se constitui com base em figuras de sentido cuja origem não está no prórpio sistema simbólico das representações visuais, mas sim em um outro tipo de código, mais analítico do que ele: no caso das imagens, portanto, há que se considerar o papel mais fundamental que os códigos perceptivos aportam, no modo como a representação é capaz de instaurar um mundo visual e de se reportar a ele, através das formas representacionais particulares. Isto tudo significa que a suposta língua das imagens é, em muitos casos, 0 efeito de uma síntese que os códigos da representação visual realizam, a partir de entidades originárias da experiência perceptiva (esta tomada em seu aspecto estrutural, e não empírico).

Do ponto de vista da consideração sobre o papel dessas figuras na constituição de um sentido discursivo ou comunicacional das imagens, teríamos que considerar uma hipotética complementação de uma abordagem semiótica dos ícones visuais por questões oriundas das abordagens psicológicas sobre fatos perceptivos. Mais uma vez, veremos o quanto essa ordem de questões envolve a necessidade de que completemos as abordagens metodológicas das teorias do signo e da interpretação por aquelas que nos são aportadas pelas disciplinas do artístico.

Dentre os autores que Umberto Eco mobiliza com maior freqüência, na discussão acerca dos aspectos ao mesmo tempo convencionais e psicológicos implicados na caracterização de uma discursividade plástica e visual (nas artes e na comunicação mediática), encontraremos 0 nome de Gombrich e a discussão que o tornou um clássico da história e da teoria da arte acerca dos elementos estruturais de uma psicologia da representação figurativa $(\mathrm{ECO}, 1968)$. 
É justamente em sua obra seminal, Art and

Illusion (GOMBRICH, 1959), que encontramos um forte discurso sobre a necessidade de se avaliar a pertinência da questão da ilusão e das estratégias da representação figurativa, nem tanto no âmbito das grandes tradições artísticas, mas no que Gombrich designa como sendo o "comércio diário com figuras e imagens de toda espécie": devemos estar atentos a não recuperar o tema da ilusão como se fosse um motivo para reintroduzir na discussão sobre as artes visuais a questão dos vínculos ontológicos entre representação e realidade. Não obstante, temos em vista ainda hoje uma espécie de franquemento das estratégias de apelo figurativo que pareceriam à tradição artística algo próximo do mágico: 0 interesse histórico pelo tema da ilusão artística é algo que se põe contemporaneamente na exata medida do barateamento de uma experiência da figuração na atualidade.

0 tratamento isolado que possamos propiciar ao debate entre Eco e Gombrich revelará, em nossa opinião, um aspecto central de uma abordagem ecológica ou perceptualista dos significados visuais (e que instanciará, igualmente, os pontos de contato que propomos aqui entre as abordagens da semiótica, da estética e da história da arte): este ponto diz respeito às teses gombricheanas acerca do esquematismo último da representação pictórica, sendo a este propósito que Eco faz menção aos problemas centrais de Art and Illusion, sobretudo na segunda parte de La Strutura Assente, quando discute as relações entre 0 problema da representação de propriedades visuais do espaço e o desenvolvimento de códigos propriamente estéticos (EC0, 1968).

Mais do que isso, o contato (polêmico ou não) entre Eco e Gombrich nos serve como sinalização para esta complementaridade possível entre as abordagens textuais da imagem (de inspiração predominantemente semiótica) e aquelas que valorizam na representação os aspectos, por assim dizer, internos de sua constituição. De fato, o recurso a idéias como as de Gombrich nos convida praticamente a uma excursão que nos conduzirá ao estilo de toda uma tradição de reflexão sobre fatos artísticos que poderia ter, por sua vez, enorme valia para uma aproximação à dimensão comunicacional das representações visuais: há um volume considerável de referências a esses pontos de contato entre as disciplinas da interpretação e as ciências da arte, e que parecem justificar o esforço pelo estabelecimento de algum tipo de contato mais produtivo entre esses campos, sobretudo numa área de estudos como a da comunicação. ${ }^{3}$

Não enumeraremos a imensa quantidade de literatura secundária acerca das relações entre as disciplinas do campo das artes e as teorias da interpretação. Preferimos apenas nos restituir a um dos marcos fundamentais desse possível ponto de encontro entre o valor da obra visual e as condições de sua interpretação: destacamos aqui o papel que a proposição de uma disciplina como a iconologia teve no sentido de dimensionar o valor das obras de uma tradição como decorrência do modo como seus temas e figuras centrais são permanentemente avaliados, através de uma interpretação regrada (de tal modo que sua análise histórica passa a colocar no centro das atenções a questão dos métodos cogitativos empregados nessa mesma avaliação). 0 programa avançado destas pesquisas é sumariado exemplarmente por Panofsky, na introdução de seu Meaning in the Visual Arts (PANOFSKY, 1979). 
No caso específico da tradição à qual se encontra vinculado o trabalho de Gombrich, 0 aspecto mais interessante de sua assimilação às abordagens semióticas da análise das representações visuais parece decorrer justamente de uma falta constitutiva de seu projeto original de pesquisa: certos comentadores de sua obra ressaltam esse dado de tensão que marca a origem mesma da investigação gombricheana sobre os mistérios do estilo na história, justamente quando essa exploração passa a valorizar aspectos da gênese das formas visuais que 0 afastam da possibilidade de uma compreensão sobre a dimensão temporal (ou histórica) desse mesmo processo (LOPES, 1996).

\section{A animação na imagem fixa e os princípios de uma discursividade icônica}

Curiosamente, entretanto, é desta mesma tensão entre duas dimensões constitutivas dos fatos artísticos (isto é, o apelo que toda representação faz às condições de sua percepção, de um lado, e 0 fato de que essas mesmas condições se manifestam de modo diverso, conforme condições culturais e históricas específicas) que nos permitirá assimilar o estilo no qual Gombrich formula uma questão de história da cultura, mas sem reter dela os aspectos que são próprios à exploração de um historiador das formas artísticas.

A capacidade de fazermos emergir a propriedade dos instrumentais analíticos e descritivos desse gênero de análise histórica em Gombrich, e deixarmos sedimentar-se 0 horizonte prático dessa indagação é 0 que nos permitirá endereçarmos 0 trabalho do historiador da arte em sua validade teórico-metodológica para a análise dos materiais visuais de nossa própria época.

Com isso, queremos dizer que certas questões de método do historiador da arte podem ter alguma incidência no modo como podemos explorar, no universo das representações visuais do campo mediático, a presença de uma regência discursiva: assumimos que a origem dessa mesma regência diz respeito, por sua vez, ao modo como a dimensão visual destes ícones é organizada enquanto matriz de significações relativamente independentes das formas que essas constrições assumem no tempo (mas certamente dependentes, por sua vez, de condições dadas no plano de uma estrutura perceptiva).

Tratemos dessa hipotética proximidade de métodos entre a semiótica e as ciências da arte, a partir de alguns casos concretos: em nossas próprias investigações sobre as modalidades de discursividade visual próprias ao fotojornalismo, temos explorado certos insights de Gombrich sobre a função dos gestos e da atitude corporal na configuração de um sentido narrativo para representações pictóricas como um modelo de análise de nossos próprios materiais (sobretudo no modo como essas imagens se restituem a contextos de uma ação que foi reportada visualmente). 
Há, por exemplo, uma mui característica complementaridade entre 0 modo como 0 arresto da imagem fixa um valor expressional para 0 gesto humano, e o caráter indicativo que esse mesmo gesto assume para a disposição de uma personagem para a ação (ou como indicativo das paixões a que ela está submetida), e que demarca, por sua vez, o estilo no qual muitas fotografias se restituem a um contexto narrativo ou dramático dos acontecimentos que elas representam.

Com isso, dizemos que a mera impregnação indexical, propiciada pela natureza do dispositivo fotográfico, não é capaz de explicar como é que assimilamos essa imagem a um determinado valor de discurso: para que isso se dê, é evidente que 0 arresto da expressão gestual das personagens tenha se coligado com uma espécie de cânone das representações da atitude e das paixões humanas, na pintura e na escultura.

Um modo possível de enquadrar esse aspecto da significação gestual é o de reconhecer, especialmente em seu emprego na representação visual, sua dimensão de ato ritualizado: na perspectiva de certos historiadores da arte, é o caráter fortemente convencionado de certos gestos que oferece à pintura os materiais pelos quais a apresentação dinâmica dos motivos, na percepção, será selecionada para a representação pictórica.

É precisamente este aspecto ritualizado das atitudes e das paixões corporais que leva Gombrich a tematizar o problema da representação dos gestos, como que cindido entre a expressividade (inerente aos sintomas) e a ritualidade (própria, por seu turno, aos símbolos): assim sendo, é evidente que a gramaticalidade das expressões gestuais oferece uma espécie de estrutura de base, sobre a qual podemos compreender 0 modo como 0 artista apreende a comunicação entre os elementos vivos de uma composição (sejam estes humanos ou não). Nesse ponto do argumento gombricheano, muitos comentadores identificam na questão do caráter codificado do gesto o prosseguimento de uma questão permanentemente posta para a história da arte, em seu status de disciplina científica, a saber, o da natureza de determinação dos estilos pictóricos: no caso da linhagem de onde as questões de Gombrich se derivam, esse é 0 problema da gênese de uma cultura visual clássica, no Renascimento, e 0 fato de que esta assimilação dos modelos representacionais da Antigüidade se opera através do que Aby Warburg chamará de "fórmulas do patético" (GUINZBURG, 1990).

A representação dos motivos dinâmicos na arte da Renascença florentina oferece ao historiador uma série de elementos formais (que se consubstanciam em autênticas tópicas figurativas), e que sinalizam a presença de uma concepção clássica da expressão visual que faz coligarem-se, por sua vez, a cultura visual da Antigüidade e o modelo da representação próprio da Renascença. 
Desse modo, a abordagem que Gombrich nos oferece sobre os aspectos ritualísticos e expressionais que encontramos no tratamento da atitude humana em representações de ações nos põe em contato com uma riquíssima chave metodológica para a interpretação destes mesmos motivos, no contexto do fotojornalismo, por exemplo, desde que sejamos capazes de separar da análise dos operadores internos desses materiais (ao menos, momentaneamente) os propósitos que inspiram uma abordagem como a de Gombrich (e o modo como ela se liga a um programa de pesquisas como o da iconologia, a partir de Warburg).

Neste caso, temos que negligenciar (mais uma vez, provisoriamente) o fato de que as relações entre imagem e regimes textuais remonta à caracterização do que Gombrich designa como sendo a "revolução grega" nas artes visuais, isto é, o momento em que a cultura artística da Antigüidade clássica passou a assimilar princípios miméticos da construção de representações de ações, agora no contexto da representação pictórica e escultórica: há um aspecto da questão que é tipicamente próprio à indagação sobre uma história dos estilos artísticos e que, justamente por isso, requer que a identificação de certos traços internos da manifestação das formas expressivas estejam permanentemente correlacionados com uma investigação sobre os padrões culturais de certas épocas e períodos.
No caso da assimilação dos padrões da composição de ícones visuais às regras da imitação na poesia dramática, é necessário considerar-se (na perspectiva do historiador) os tipos de demanda feitos ao campo artístico, em certos períodos: aparentemente, segundo Gombrich (1959), há uma passagem na arte da Antigüidade clássica na qual os motivos da representação começam a deixar de atender a finalidades próprias de uma arte conceitual (a rememoração, o culto à permanência) para exprimir visualmente 0 sentido da mudança, da transformação (próprios à representação das ações através da narrativa); este aspecto de contextualização temporal de uma interrogação às funções textuais da imagem é algo que devemos ter em vista, em nossas próprias investigações, mas apenas como um dado de pressuposto sobre os limites preliminares entre as abordagens semióticas da imagem e aquelas que definem 0 interesse das ciências da arte, em geral, sobre o mesmo tópico.

Por outro lado, é evidente que a novidade de uma abordagem sobre as transformações do estilo figurativo, propostas por Gombrich, implicam em um aprofundamento de questões que a tradição da história da arte não teria podido explorar com fecundidade, se mantivesse seu foco de interesse concentrado nos limites de seus próprios instrumentais conceituais e metodológicos.

Vários comentadores dessa tradição que constituiu a iconologia como uma disciplina régia 
dos estudos sobre fatos artísticos ressaltam 0 valor próprio que caracteriza a abordagem de Gombrich (muito especialmente esse aspecto da introdução dos saberes psicológicos para a compreensão do modo como os estilos visuais se sedimentam), sobretudo em comparação com o modo como a linhagem intelectual que o gerou havia enfrentado o desafio de uma história dos estilos artísticos; e é precisamente esse aspecto da assimilação de uma psicologia da representação pictórica num projeto de periodização dos estilos que devemos contemplar como chave para a discussão sobre a natureza dos regimes textuais nos quais encontramos a imagem visual funcionando, em nossos dias (GUINZBURG, 1990).

Um aspecto essencial do modo como certas teorias semióticas tentaram incorporar à análise do valor discursivo da imagem os aspectos de articulação próprios à matéria icônica das representações visuais é 0 fato de que essas mesmas teorias (como parece ser o caso de Umberto Eco) incluem problemas de psicologia da percepção na análise da representação visual: nestes termos, concluímos que a questão da compreensão da imagem em termos de seus regimes textuais de significação assume precisamente 0 estatuto de uma interrogação próprio a uma experiência perceptiva (e, por isso mesmo, estética), esta tomada em seu sentido mais lato possível.

Assim, o modo como compreendemos uma representação visual não deriva de sua capacidade de ser codificada num plano metasemiósico (como no caso das teorias semiológicas de primeira geração), mas se impõe à experiência como uma presença hipnótica, ainda que haja uma tarefa própria à instância da recepção, na constituição dos percursos visuais através dos quais as formas pictóricas serão restituídas a seu poder de comunicação (COMETTI; MORIZOT; POUIVERT, 2000).

Nesse sentido, devemos conceber que se estabelecem entre abordagens semióticas e estéticas um insuspeito vínculo cooperativo: ainda que 0 efeito da imagem se ofereça no modelo de uma visibilidade de segunda ordem, do ponto de vista da compreensão, esta vicariedade da visão representacional é assimilada como um regime de leitura, no modo como certos semiólogos da segunda geração pensam a respeito de um princípio textual de organização dos materiais visuais na sua forma representacional.

Como reforço a este primeiro aspecto, podemos estabelecer que 0 interesse de uma teoria da representação visual não poderia ficar restrito ao universo empírico das imagens artísticas (justamente por isso, insistimos, logo acima, no caráter mais genérico do atributo estético de sua experiência), e que uma estética das representações pictóricas deveria, portanto, estar antecedida de uma interrogação estética sobre as representações visuais em geral, em todos os seus variáveis usos e aplicações no contexto de nossa cultura. 
Assim sendo, não se deveria restringir seu campo de observação às imagens figurativas, compostas com o fim de gerar um tipo de experiência puramente fruitiva (como é o caso das imagens artísticas), mas também as funções que caracterizam a compreensão de figurações como as que encontramos em mapas, em imagens de notas de moeda corrente, cenas mitológicas, sinais heráldicos, marcas de produtos e instituições, entre outros.

0 estudo das assim designadas "imagens demóticas" estabelece que o universo da representação estética mantém uma relação fundamental com regimes outros nos quais encontramos o funcionamento desse tipo de imagens: podemos até mesmo estabelecer uma espécie de paralelo entre 0 tratamento estético propiciado a elas e aquele que nobilita, na filosofia da linguagem, a importância atribuída ao universo da linguagem ordinária; aqui e ali, as realizações propriamente estéticas e lingüísticas mais "elevadas" (no campo, por exemplo, das metáforas e das alegorias) encontram suas raízes deitadas na estrutura do discurso comum e das relações com as imagens da cultura contemporânea.

\section{Referências Bibliográficas}

BARTHES, Roland. "La rhétorique de l'image». In: Communications, n. 4, p. 40-51, 1964.

CAUNE, Jean. Esthétique de la Communication. Paris: PUF, 1997.

COMETTI, Jean-Pierre; MORIZOT, Jacques; POUIVET, Roger. Questions d'esthétique. Paris: PUF, 2000.
EC0, Umberto. La Struttura Assente. Milano: Bomipiani, 1968.

FRESNAULT-DERUELLE, Pierre. Le verbal dans les bandes dessinées. Communications, n. 15, p. 145161, 1970 .

GOMBRICH, E.H. Art and illusion: a study in the psychology of pictorial representation. New York: Princeton University Press, 1959. Image and word in 20th century art". Word and image, n. 1, vol. 3, 1985, p. 213-241. The wit of Saul Steinberg. Art Journal, winter, 1983, p. 377-380.

GUINZBURG, Carlo. De A. Warburg a E.H. Gombrich: notas sobre um problema de método. In: Mitos, emblemas, sinais: morfologia e História. Tradução: Federico Carotti. São Paulo: Cia das Letras, 1990, p. 41-94. LOPES, Dominic. Understanding Pictures. 0xford: Clarendon Press, 1996.

PANOFSKY, Erwin Iconografía e Iconología: introducción al estudio del arte del Renacimiento. In: El Significado em las Artes Visuales (trad. Nicanor Ancochea). Madrid: Alianza, 1979. p. 45-75.

PARRET, Herman. Comunicar por aisthèsis. In: A estética da comunicação. Tradução: Roberta Pires de Oliveira. Campinas: Unicamp, 1997, p. 183-203.

PICADO, Benjamim. Olhar testemunhal e representação da ação na fotografia. In: E-Compós, vol. 3, n. 1, pp. 2-29, 2005. Disponível em: < http:// www.compos.org.br/seer/index.php/e-compos/article/ view/41/41>. Acesso em: 13 abr. 2008.

Os desafios metodológicos da leitura das imagens: um exame crítico da semiologia visual. Fronteiras: estudos mediáticos, vol. 4, n. 2, p. 5670, 2003.

Do problema do iconismo à ecologia da representação pictórica: indicações metodológicas 
para a análise do discurso visual. Contracampo. vol. 9, n. 2, p. 95-123, 2004.

Ícones, Instantaneidade e Interpretação: por uma pragmática da recepção pictórica na fotografia.

Galáxia, n. 9,p. 159-184, 2005.

SCHAPIRO, Meyer. Les mots et les images. Paris :

Macula, 2000.

On some problems in the semiotics of visual

arts: field and vehicle in image-signs. Semiotica, n. 1, vol. 3, p. 223-242, 1969. 


\section{Ways of understanding images: method questions on the textual analysis of visual representations}

\section{Abstract}

We intend to present a brief panorama of the points of contact between two approaches towards the analysis of images, one from semiotics, the other from aesthetics: we take as a standpoint the assumption about the discursive regimes that define the uses of visual representation, in the context of mass communications: in acknowledgement of the dominance of the views of semiotics on the matter, we intend to take into account the perspectives brought about by sciences of art (specially the in the methodological questions introduced by some historians of paintings), assuming to find in these theories certain ways of addressing the psychological structures of the experience of interpreting and appreciating visual icons, which could not be disregarded by a theory of image understanding which assumes that visual icons also function as textual forms.

\section{Keywords}

Image analysis. Semiotics. Art Sciences.

\section{Modos de comprender imágenes: cuestiones de método sobre el análisis textual de las representaciones visuales}

\section{Resumen}

Proponemos un panorama breve de los puntos de contacto entre los abordajes semióticos y estéticos del análisis de las imágenes, teniendo en cuenta el régimen discursivo que las demarca, especialmente en el contexto de la comunicación: reconociendo la predominancia histórica de las perspectivas que la semiología ha aportado a la discusión sobre las regencias textuales de las representaciones visuales, buscamos introducir al debate el punto de vista que las ciencias del arte (muy especialmente las cuestiones de método de abordaje histórico de los hechos artísticos), suponiendo encontrar allí ciertos modos de aproximación a la estructura psicológica de la experiencia de los íconos y de su interpretación y fruición que no podrían ser descuidadas por una teoría de la comprensión de la imagen como forma textual.

\section{Palabras clave}

Análisis de imágenes. Semiótica. Ciencias del Arte. 


\section{Expediente}

A revista E-Compós é a publicação científica em formato eletrônico da Associação Nacional dos Programas de Pós-Graduação em Comunicação (Compós). Lançada em 2004, tem como principal finalidade difundir a produção acadêmica de pesquisadores da área de Comunicação, inseridos em instituições do Brasil e do exterior.
E-COMPÓS I www.e-compos.org.br I E-ISSN 1808-2599

Revista da Associação Nacional dos Programas de Pós-Graduação em Comunicação. Brasília, v.11, n.2, maio/ago. 2008

A identificação das edições, a partir de 2008 passa a ser volume anual com três números.

\section{CONSELHO EDITORIAL}

\section{Afonso Albuquerque}

Universidade Federal Fluminense, Brasil

Alberto Carlos Augusto Klein

Universidade Estadual de Londrina, Brasi

Alex Fernando Teixeira Primo

Universidade Federal do Rio Grande do Sul, Brasi

Alfredo Vizeu

Universidade Federal de Pernambuco, Brasil

Ana Carolina Damboriarena Escosteguy

Pontifícia Universidade Católica do Rio Grande do Sul, Brasil

Ana Silvia Lopes Davi Médola

Universidade Estadual Paulista, Brasil

André Luiz Martins Lemos

Universidade Federal da Bahia, Brasil

Ângela Freire Prysthon

Universidade Federal de Pernambuco, Brasil

Antônio Fausto Neto

Universidade do Vale do Rio dos Sinos, Brasil

Antonio Carlos Hohlfeldt

Pontifícia Universidade Católica do Rio Grande do Sul, Brasil

Arlindo Ribeiro Machado

Universidade de São Paulo, Brasil

César Geraldo Guimarães

Universidade Federal de Minas Gerais, Brasi

Cristiane Freitas Gutfreind

Pontifícia Universidade Católica do Rio Grande do Sul, Brasil

Denilson Lopes

Universidade Federal do Rio de Janeiro, Brasil

Eduardo Peñuela Cañizal

Universidade Paulista, Brasil

Erick Felinto de Oliveira

Universidade do Estado do Rio de Janeiro, Brasil

Francisco Menezes Martins

Universidade Tuiuti do Paraná, Brasil

Gelson Santana

Universidade Anhembi/Morumbi, Brasil

Hector Ospina

Universidad de Manizales, Colômbia

leda Tucherman

Universidade Federal do Rio de Janeiro, Brasil

Itania Maria Mota Gomes

Universidade Federal da Bahia, Brasil

Janice Caiafa

Universidade Federal do Rio de Janeiro, Brasil

Jeder Silveira Janotti Junior

Universidade Federal da Bahia, Brasil
John DH Downing

University of Texas at Austin, Estados Unidos

José Luiz Aidar Prado

Pontifícia Universidade Católica de São Paulo, Brasil

José Luiz Warren Jardim Gomes Braga

Universidade do Vale do Rio dos Sinos, Brasi

Juremir Machado da Silva

Pontifícia Universidade Católica do Rio Grande do Sul, Brasil

Lorraine Leu

University of Bristol, Grã-Bretanha

Luiz Claudio Martino

Universidade de Brasília, Brasil

Maria Immacolata Vassallo de Lopes

Universidade de São Paulo, Brasil

Maria Lucia Santaella

Pontifícia Universidade Católica de São Paulo, Brasil

Mauro Pereira Porto

Tulane University, Estados Unidos

Muniz Sodre de Araujo Cabral

Universidade Federal do Rio de Janeiro, Brasil

Nilda Aparecida Jacks

Universidade Federal do Rio Grande do Sul, Brasil

Paulo Roberto Gibaldi Vaz

Universidade Federal do Rio de Janeiro, Brasil

Renato Cordeiro Gomes

Pontifícia Universidade Católica do Rio de Janeiro, Brasil

Ronaldo George Helal

Universidade do Estado do Rio de Janeiro, Brasil

Rosana de Lima Soares

Universidade de São Paulo, Brasil

Rossana Reguillo

Instituto Tecnológico y de Estudios Superiores do Occidente, México

Rousiley Celi Moreira Maia

Universidade Federal de Minas Gerais, Brasil

Sebastião Carlos de Morais Squirra

Universidade Metodista de São Paulo, Brasil

Simone Maria Andrade Pereira de Sá

Universidade Federal Fluminense, Brasil

Suzete Venturelli

Universidade de Brasília, Brasil

Valério Cruz Brittos

Universidade do Vale do Rio dos Sinos, Brasil

Veneza Mayora Ronsini

Universidade Federal de Santa Maria, Brasil

Vera Regina Veiga França

Universidade Federal de Minas Gerais, Brasil

\section{COMISSÃO EDITORIAL}

Ana Gruszynski I Universidade Federal do Rio Grande do Sul, Brasil João Freire Filho I Universidade Federal do Rio de Janeiro, Brasil Rose Melo Rocha I Escola Superior de Propaganda e Marketing, Brasil

\section{CONSULTORES AD HOC}

Aníbal Bragança I Universidade Federal Fluminense, Brasil Gisela Castro I Escola Superior de Propaganda e Marketing, Brasil

Gislene Silva I Universidade Federal de Santa Catarina, Brasil

Maria Helena Weber I Universidade Federal do Rio Grande do Sul, Brasil

Rosana de Lima Soares I Universidade de São Paulo, Brasil

Tania Hoff I Escola Superior de Propaganda e Marketing, Brasil

REVISÃO DE TEXTO E TRADUÇÃo I Everton Cardoso

ASSISTÊNCIA EDITORIAL E EDITORAÇÃO ELETRÔNICA I Raquel Castedo
COMPÓS I www.compos.org.br

Associação Nacional dos Programas de Pós-Graduação em Comunicação

Presidente

Erick Felinto de Oliveira

Universidade do Estado do Rio de Janeiro, Brasil erickfelinto@uol.com.br

Vice-presidente

Ana Silvia Lopes Davi Médola

Universidade Estadual Paulista, Brasil

asilvia@faac.unesp.br

Secretária-Geral

Denize Correa Araújo

Universidade Tuiuti do Paraná, Brasil

denizearaujo@hotmail.com 